\title{
Did Martian valley networks substantially modify the landscape?
}

DOI:

10.1016/j.epsl.2020.116482

\section{Document Version}

Accepted author manuscript

Link to publication record in Manchester Research Explorer

\section{Citation for published version (APA):}

Grau Galofre, A., Bahia, R. S., Jellinek, A. M., Whipple, K. X., \& Gallo, R. (2020). Did Martian valley networks substantially modify the landscape? Earth and Planetary Science Letters, 547, 116482.

https://doi.org/10.1016/j.epsl.2020.116482

\section{Published in:}

Earth and Planetary Science Letters

\section{Citing this paper}

Please note that where the full-text provided on Manchester Research Explorer is the Author Accepted Manuscript or Proof version this may differ from the final Published version. If citing, it is advised that you check and use the publisher's definitive version.

\section{General rights}

Copyright and moral rights for the publications made accessible in the Research Explorer are retained by the authors and/or other copyright owners and it is a condition of accessing publications that users recognise and abide by the legal requirements associated with these rights.

\section{Takedown policy}

If you believe that this document breaches copyright please refer to the University of Manchester's Takedown Procedures [http://man.ac.uk/04Y6Bo] or contact uml.scholarlycommunications@manchester.ac.uk providing relevant details, so we can investigate your claim.

\section{OPEN ACCESS}




\title{
Did Martian valley networks substantially modify the landscape?
}

\author{
Anna Grau Galofre ${ }^{\mathrm{a}}$, Rickbir SinghBahia ${ }^{\mathrm{b}}$, A. Mark Jellinek ${ }^{\mathrm{c}}$, Kelin X. \\ Whipple $^{\mathrm{a}}$, Rose Gallo ${ }^{\mathrm{d}}$ \\ ${ }^{a}$ School of Earth and Space Exploration, Arizona State University \\ ${ }^{b}$ School of Earth, Atmospheric and Environmental Sciences, The University of Manchester \\ ${ }^{c}$ Department of Earth, Ocean, and Atmospheric Sciences, University of British Columbia \\ ${ }^{d}$ School of Earth and Sustainability, Northern Arizona University
}

\begin{abstract}
Valley networks are ancient drainage systems incised on the southern hemisphere of Mars, and stand as evidence that liquid water once sculpted its surface. The duration of valley network activity and the sources of water are key questions in deciphering the timing of water stability on early Mars, but remain poorly constrained. In this study we address two questions: Did Martian valley networks evolve for sufficiently long to establish their own erosional basins, or do their profiles primarily reflect landscape pre-incision topography? And were these valleys precipitation-fed or spring-fed? Our analysis uses the theoretical framework built to describe the shape of steady-state river profiles on Earth to compare and analyze the concavity of 62 valley network longitudinal profiles on Mars. Using non-linear fits to valley profiles we evaluate the degree to which valley networks are consistent with fluvial steady-state. The fit enables the identification of valley network concavity index and area-discharge exponent, which we then interpret in terms of the theoretical framework to discuss valley network maturity and water source. Our results show that the majority of valley networks do not have concave or even smooth profiles, and did not substantially
\end{abstract}

${ }^{*}$ Corresponding author: Anna Grau Galofre (agraugal@asu.edu)

Preprint submitted to Earth and Planetary Science Letters

June 2, 2020 
modify their surrounding landscape. We observe disparity in concavity indexes of valley networks belonging in the same integrated basins, indicating different stages of landscape evolution and lack of synchronous valley development. However, our results identify six valley networks consistent with fluvial steady-state and areally uniform precipitation.

Keywords: Mars, Valley networks, Maturity, Fluvial erosion, Profile analysis, Precipitation

\section{Introduction}

Thousands of valley networks are etched into the southern hemispheric highlands of Mars, standing as evidence that water sculpted the ancient surface of the planet. Martian valleys are dendritic tributary networks incised mostly into the heavily cratered ancient Noachian terrains $(\sim 3.8 \mathrm{Ga})$. A heated matter for debate is the requirements that the presence and morphology of these valley networks place on early Mars climate [1, 2, specifically whether liquid water was stable for long or short periods of time on the surface of Mars.

Although it is generally agreed that liquid water was involved in valley formation, controversy remains over the duration and intensity of the erosion episodes [3, 4, 1, 5, 6, 7, 8, as well as over the source of the water: rainfall [1, 6, 9, 8], snowfall and snowmelt [10, 2], groundwater seepage [11, 12, 4] (see however [13]), etc. Here we seek to answer two questions: Were valley networks active for long enough to significantly alter the landscape, and generate well-established drainage basins? Was precipitation-driven runoff required or could groundwater produce the observed landforms?

A way to evaluate the extent to which fluvial processes have modified the landscape is to interrogate the concavity index (slope-area exponent) of valley longitudinal profiles in terms of the theory describing river valleys in steady-state [e.g., 14, 15, 16, 17]. "Mature" river valleys reflect in the concavity of their 
smooth profiles either a balance of tectonic uplift and erosion rates (bedrock rivers) or a local equilibrium between sediment transport capacity and sediment supply (alluvial rivers) [e.g., 14, 15, 17, 18. The characterization of river concavity in the context of landscape equilibrium has been the focus of much attention for terrestrial rivers [e.g., 14, 15, 16, 17, 19, 18. On Mars, several studies have extracted valley profile concavity from area-slope scaling laws, and compared it qualitatively to terrestrial standards [e.g., 20, 5, 21, 22, 23]. The focus and novelty of this study is to apply the terrestrial theoretical framework to help interpret the concavity of a large number of Martian profiles, with focus on their maturity and the characteristics of the runoff source.

\subsection{Structure}

We compare the concavity of main stem profiles to steady-state solutions of fluvial landscape evolution equations [16, 19, 18. Using a dataset of 62 valley network longitudinal profiles, we show how each profile compares to (or departs from) steady-state model predictions, and identify those valley networks that have substantially modified the landscape around them. We then compare our results with observations drawn from morphological metrics commonly invoked to assess the degree of valley maturity [24, 25, 8]. We discuss the distribution of valley networks with profiles consistent with fluvial landscape equilibrium, and for these systems, we characterize the water sources expected for the drainage basins [16, 7, 18]. We finish by considering the results obtained in the context of three large integrated basins: the Loire-Parana-Samara, the Naktong-Scamander-Mamers, and the Evros-Mosa drainage systems.

\section{The concavity of steady-state fluvial profiles}

Historically, the formation of the Martian valley networks has been attributed either to surface runoff [1, 7, 6, 9], or to groundwater sapping [1], 
26, 4]. Fluvial erosion can occur in two regimes: bedrock rivers (the so-called detachment-limited regime [16, 7]) erode the bed via the sediments they carry through a combination of plucking and abrasion [17; and alluvial rivers erode substrates that offer low resistance to detachment, erosion, and transport (the so-called transport-limited regime, [17, 18).

On Earth, tectonic uplift and the resulting production of steep topography yield the high shear stress conditions necessary for the formation of bedrock rivers. Lacking orogenesis, craters dominate the regional slopes, whereas Tharsis and the dichotomy boundary set the long-wavelength Martian topography. Craters disrupt the landscape, produce highly erodible ejecta and hard crater floors, and have a long-term diffusive effect on the landscape [7. Whereas stratigraphy shows that bedrock rivers existed on Mars 9, it is likely that the gentler slopes and more friable substrates characteristic of the intracrater plains led to the development of alluvial valley networks.

Erosion by sapping constitutes another hypothesis for valley network formation [11, 26, 4], although it is problematic in cohesive substrates [13, 27]. Sapping valleys develop when groundwater emerges at a spring, producing erosion at the site of seepage leading to the headwards development of a valley. The steady-state shape of sapping valley longitudinal profiles is governed by distinct physics at two length scales. Near the spring, the longitudinal profile decreases with the distance from the tip with an exponent of $2 / 3$ [28]. However, at the valley network basin length scales (100-1000 km) [5], erosion by surface runoff dominates the formation and shape of the drainage network 28. A sapping signature should only be apparent in the first order tributaries [28].

Coherently, here we build upon a theoretical framework describing basinscale valley network longitudinal profiles that includes both alluvial and bedrock rivers, but not sapping valleys. 


\subsection{Modeling the effects of fluvial erosion}

Steady-state river longitudinal profiles are empirically described by Flint's law (equation 1), which relates slope $\partial z / \partial x$ and upstream drainage area or length $x$ (through Hack's length-area relationship $A=K_{a} x^{h}$ [29]). Previous work has demonstrated that valley networks also follow a slope-area scaling [23, 30]:

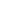

$$
\frac{\partial z}{\partial x}=K_{s}\left(K_{a} x^{h}\right)^{-\theta}
$$

where $K_{s}$ is the steepness index, $K_{a}$ is Hack's law parameter, $h$ is Hack's exponent, and $\theta$ is the concavity index. Direct integration of this equation assuming that all variables are spatially homogeneous yields the empirical shape of a steady-state fluvial profile, where $L$ is the basin length:

$$
z(x)=K_{s} K_{a}^{-\theta}(1-h \theta)^{-1}\left[L^{1-h \theta}-x^{1-h \theta}\right] .
$$

The form of equation 2 describes both alluvial and bedrock equilibrium river profiles [16, 17, 18] independently of gravity, making it applicable to any solar system body. Whereas the concavity index $\theta$ of a steady-state river varies within a narrow, distinctive range [14, 16, 17, 18, the interpretation of the coefficient $K_{s}$ differs depending on the erosive regime. The existence of a general form describing transport and detachment-limited river profiles in equilibrium 2 allows for the identification of valley networks consistent with fluvial steady-state without making assumptions regarding the mechanics of landscape equilibrium, as developed below. As a result, our methods and conclusions are easily extendable to previous morphometrical analysis of profile concavity [20, 22, 23.

\subsubsection{Steady-state fluvial longitudinal profiles}

Under the detachment-limited regime, the longitudinal profile form of a bedrock river in steady-state is given by the solution to the stream-power law, 
which in non-dimensional form is written [e.g., 14, 16, 17, 7]:

$$
z_{*}\left(x_{*}\right)=z_{*}(1)-N_{e}^{1 / n} U_{*}^{1 / n}(1-h m / n)^{-1}\left(1-x_{*}^{1-h m / n}\right),
$$

where $z_{*}$ and $x_{*}$ are non-dimensional elevation and length, $U_{*}$ is the normalized uplift rate, $n$ is the slope exponent, $m / n$ is the bedrock concavity index, and the non-dimensional uplift-erosion number $N_{e}$ contains the dimensional information [16. This equation can be rewritten to recover the form of equation 2 [16:

$$
z_{*}=K_{d}-K_{d} x_{*}^{1-h \theta}
$$

The two coefficients in equation 4 can be identified with those in equation 3 as a function of the steepness index $K_{d}=K_{s} K_{a}^{-\theta}(1-h \theta)^{-1} L^{1-h \theta}$ and concavity index $m / n=\theta$.

Considering now transport-limited rivers and assuming negligibly small uplift rates $(U \rightarrow 0)$, the steady-state profile of an alluvial river follows (modified from equation 40 [18]):

$$
z=\left(\frac{x^{1+6 \operatorname{ch}(b-1) / 7}-x_{o}^{1+6 \operatorname{ch}(b-1) / 7}}{x_{1}^{1+6 \operatorname{ch}(b-1) / 7}-x_{o}^{1+6 \operatorname{ch}(b-1) / 7}}\right)+1
$$

where $x_{o}$ and $x_{1}$ are the positions of the origin and downstream boundary, and $b$ and $c$ are the discharge-width and the discharge-area exponents. Equation 5 can be non-dimensionalized and written to recover equations 2 and 4

$$
z_{*}=K_{t}-K_{t} x_{*}^{1-6 / 7 h \theta_{t}}
$$

With coefficient $K_{t}=K_{s} K_{a}^{-\theta}(1-h \theta)^{-1} L^{1-h \theta}$. The slight difference between the alluvial concavity index $\theta_{t}=7 / 6 \theta$ and the bedrock one $m / n=\theta$ results from different choices describing water turbulent stresses in the literature [16, 18, and 
does not affect the form or interpretation of the equation. Note also that the coefficients $K_{t}$ in 6 and $K_{d}$ in 4 are related in the same way to the steepness index $K_{s}$ but each have different definitions (5) and 3).

\subsubsection{Basin-scale valley network degradation}

Martian valley networks have been subjected to degradation processes for over 3.5 Ga. On Mars, wind, mass-wasting, cratering, and dust blanketing potentially modified the initial shape of valley networks and their profiles. Whereas it is possible for diffusive processes to erase small tributaries and higher frequency topography, it is unlikely that they had any significant effect on basinscale profile concavity. A scaling argument (supplement) shows that diffusion modifies the topography at a valley width scale by a half of local valley network depth (order $\sim 100 \mathrm{~m}$ ). The longitudinal profile shape, however, is set by total basin scale relief and length, which is at least an order of magnitude larger. The different length scales of action, exemplified by the ratio of width versus length, show that diffusion has not substantially modified longitudinal profile concavities.

\subsubsection{Parameters and exponents: building intuition}

We present a theoretical framework [16, 7, 18, to inform the interpretation of the concavity index $\theta$. The following arguments are drawn from analyzing bedrock rivers but equivalent relationships have been developed for alluvial systems [18. Derivation of erosion models part from the reasonable assumption that erosion rates have a power dependence on shear stress:

$$
E=K_{b} \tau_{b}^{a}
$$

and combines the following semi-empirical relationships from momentum conservation, hydraulic geometry, basin hydrology, and basin geometry, in turn, to 

${ }_{158} \quad n \geq 0$.

establish a closure for the shear stress $\tau_{b}$ :

$$
\begin{array}{r}
\tau_{b}=\rho g D S=1 / 2 C_{f} v^{2} \\
W=k_{w} Q^{b} \\
Q=K_{q} A^{c} \\
A=K_{h} L^{h},
\end{array}
$$

where $D$ is flow depth, and $v$ is flow velocity. Combining equation 7 with equations 8

$$
E=K A^{2 a c(1-b) / 3} S^{2 a / 3} .
$$

Comparing this equation with the closures in equations 7 and 8 , the slope exponent $n$, concavity index $m / n$, and Hack's reciprocal exponent $h$ depend on $a, b, c$ through:

$$
\begin{array}{r}
n=2 a / 3 \\
m=2 a c(1-b) / 3 \\
m / n=\theta=c(1-b),
\end{array}
$$

with $h \approx 1.35$ from empirical fits to Martian valley networks [29, 5, 21, 23. The exponent $a$ in 7 sets the intensity of the erosion rate as a function of shear stress [16], and takes values between 1 and $5 / 2$ in terrestrial bedrock rivers [e.g., 16, 19]. Erosion rates increase with basal shear stress: $a \geq 0$ and by extension,

Conservation of water mass sets the physical meaning of $b$ and $c$ at the reach $(\sim W)$ and basin scale $(\sim L)$ 7]. At the reach scale, water discharge $Q=v D W$ is a constant. Furthermore, stability of the channel cross-section imposes a linear scaling between depth and bankfull width [e.g., 31] $D \sim W$, defining the 
form of the hydraulic geometry:

$$
Q \sim W^{2},
$$

so that $b \approx 0.5$. The parameters $b$ and $k_{w}$ depend on rock mass quality, erosion process, sediment loading, and hydraulic resistance [16]. The exponent $b$ varies between $b \approx 0.4-0.6$ in alluvial rivers [31, 32] and bedrock rivers [16, 19, 33]. Whereas $b=0.5$ is a good average, we acknowledge that this exponent is empirical and has inherent variability [34, 35]. Given the limitations in constraining this variability for Mars, taking $0.4<b<0.6$ is a practical choice.

Water sources (rainfall, snowfall, groundwater seepage) and sinks (evaporation, permeation, sublimation) set the water mass transported through the drainage basin. If uniform precipitation dominates the sources, water availability increases linearly with drainage area, but the same is false if water enters the basin as point sources from localized groundwater sapping. If additionally all water collected in the basin is delivered to the outlet without any losses during its transport, or if losses also increase homogeneously with area, the water inventory in a precipitation-fed system is crudely given by:

$$
\rho_{w} \sum Q_{i} \sim K_{p r} A
$$

Precipitation minus evaporation per unit time $K_{p r}\left(\mathrm{~kg} / \mathrm{m}^{2} \mathrm{~s}\right)$ over a drainage area $A$ increases tributary discharge $Q_{i}$, which add up to produce the total discharge at the outlet (left hand side) that scales linearly with area $Q \sim A$, with $c=1$.

\subsubsection{Martian climate and the discharge-area exponent $c$}

There is an extensive body of literature that describes the role of spatial and temporal variability of runoff production through the $c$ exponent [34, 35, 
36, 37, 38. A $c=1$ exponent requires long-lasting, spatially uniform precipitation events 36, which can correspond either to homogeneous rainfall or snowfall. Non-homogeneous or unsteady rainfall, such as storm events, flooding, or sporadic precipitation yield $c<1$ [36. Similarly, topographic controls on temperature [39, 2] produce an uneven distribution of snow on the terrestrial mid-latitudes, implying $c<1$. However, in high latitude areas on Earth [39, 37, and on the Martian highlands [2] where topography is subdued, snow falls if pressure and temperature are below melting, independently of relief. Thus $c=1$ is also compatible with snowfall. In the case of groundwater seepage, discharge enters the drainage network spatially concentrated in springs, the number and flux of which does not necessarily increase with basin area 28]. This highlights an independence of discharge in the later, which should yield $c \approx 0$.

In summary, Martian fluvial valley networks in steady-state must display concave profiles as imposed by $n>0$, with a shape consistent with the predictions from equation 3 . Fluvial networks consistent with steady-state that are additionally fed by uniform precipitation (rain or snowfall) should display $\theta \approx 0.5$, following the scaling arguments presented. We can now quantitatively interrogate the concavity index $\theta$ and water mass-balance $c$ characteristics of Martian longitudinal profiles and identify the systems that have substantially modified the landscape around them.

\subsection{Evolution from initial conditions}

Profile concavity indexes $\theta<0.45$ are characteristic of systems that still reflect the initial conditions of the landscape. Contrarily, concavity indexes $0.45<\theta<0.6$ are consistent with steady-state [16, 17, 18, implying that valley networks were active for a cumulative long period of time. This is true, however, only if the initial curvature characteristics of the landscape were not already initially consistent with $\theta \approx 0.5$. 
To determine whether concavity indexes yielding $\theta \approx 0.5$ reveal a drainage basin consistent with steady-state or reflect landscape initial conditions, we compare our results to the concavity index measured for the background topography [5]. We take the reference background concavity for the appropriate Noachian terrain each valley incises (supplement) [5] as proxy for landscape initial conditions, so that there is landscape modification if $\theta>\theta_{\text {bkgrd }}$ [5]. For the valleys showing $\theta>\theta_{b k g r d}$, we additionally assess this condition by comparing curvature far away from the drainage basin area, in the basin area, and in the valley network profile, using the MOLA-derived curvature raster (supplement).

\section{Comparison of valley network profiles and steady-state model so- lutions}

\subsection{Longitudinal profile extraction}

We extracted the main stem longitudinal profile of 62 valley networks (supplementary tables 1 and 2). After selecting valley network targets of different locations, morphological characteristics, and timing of activity, we manually mapped the streamline of each network's main stem. Although a previous global map of valley streamlines exists [8, our own mapping efforts using a combination of MOLA, THEMIS, and CTX mosaics provides higher resolution streamlines (figure 1 ).

For profile extraction we use MOLA PEDR altimetry point data [6], instead of gridded MOLA/HRSC DEM data [40]. Although the nominal resolution for the MOLA gridded DEM is a few hundred meters, the spacing between laser points along a valley is variable and often up to a few kilometers. Interpolation, DEM stitching, as well as other errors can also introduce uncertainty in the MOLA DEM. To minimize these effects, we select the MOLA altimetry points that are within $100 \mathrm{~m}$ of mapped valley network stream lines (figure 1), ac- 

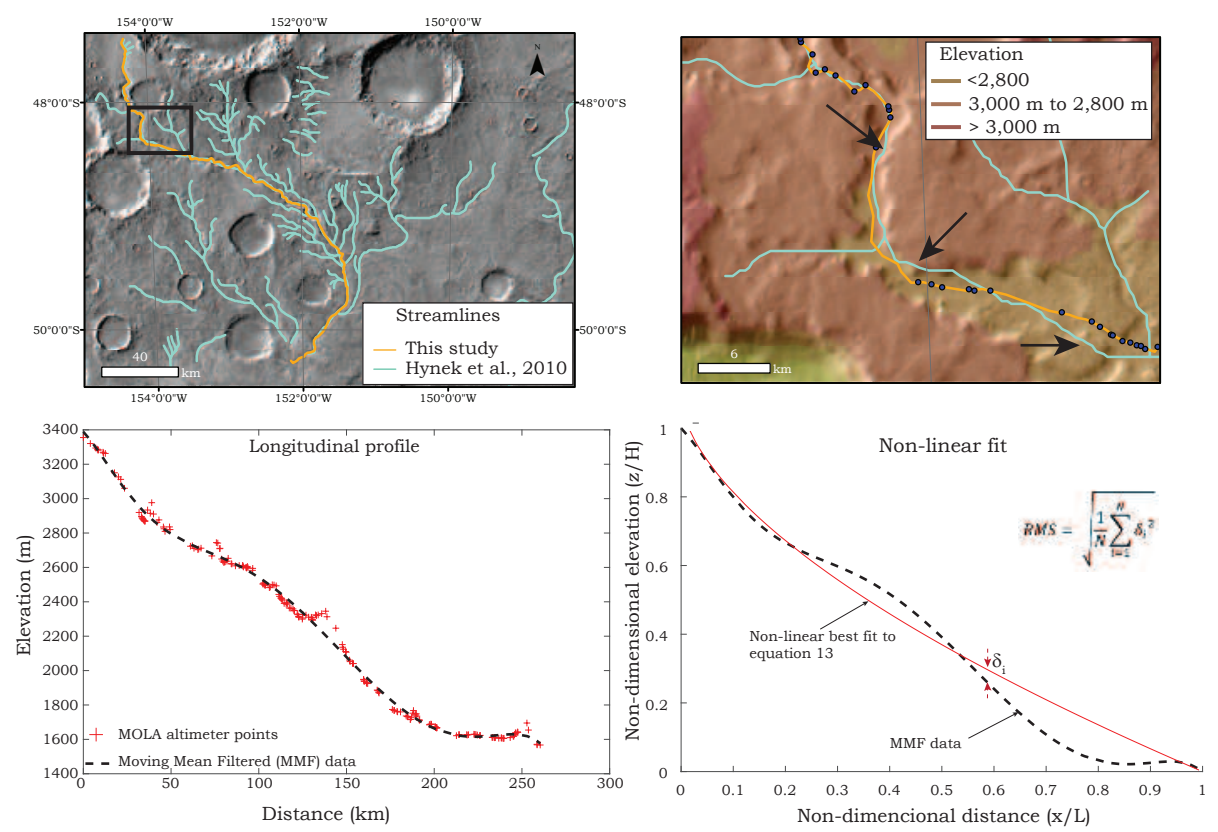

Figure 1: Mapping, extraction, filtering, and non-linear best fit to the longitudinal profile of Tader valles. (a) THEMIS mosaic overlain with the manually mapped main stem streamline (orange) compared to streamlines form Hynek et al., 2010 [8] (green) for Tader valles. (b) Box inset showing a CTX mosaic overlain with MOLA for streamline comparison (see arrows), and the extraction of MOLA PEDR data (dots) within $100 \mathrm{~m}$ of the streamline. (c) MOLA PEDR longitudinal profile of Tader valles (red crosses) and Mean Moving Filtered profile (MMF, dashed line). (d) Best fit of the MMF data to equation 13, with RMS definition.

counting for the $\approx 100 \mathrm{~m}$ MOLA laser footprint 41 . We then filter the profile using a Moving Mean Filter (MMF) with a window of 5 altimeter points. Profile disturbances much smaller than the basin length (e.g., most craters, faults, dunes) do not affect our concavity analysis.

\subsection{Non-linear regression and misfit evaluation}

We characterize the shape and curvature of valley network profiles fitting the following non-linear equation to the normalized form of each profile:

$$
z_{*}=a_{f} / b_{f}-a_{f} / b_{f} x_{*}^{b_{f}},
$$


This equation is formally equivalent to the integration of Hack's second law 2. the solution to the stream-power law 4, and the zero-uplift solution to the alluvial landscape evolution equation 6 , with $b_{f}=1-h \theta$, and $a_{f} / b_{f}$ relating to the steepness index $K_{s}$ as appropriate. Note that our approach is different from the extraction of $\theta$ directly from Flint's law (equation 1); equation 13 cannot be linearized using logarithms and requires the use of non-linear fits to the data. To extract the concavity index $\theta$ we set $1 / h \approx 0.74[5,21,23$. From best fits we extract the combination of parameters that minimize the $R M S$ misfit between each profile and the equilibrium curve predicted in equation 13 . Figure 1 shows an example of a valley network profile extraction and non-linear fit.

There are two advantages to this technique. First, this method is independent of drainage area $A$. Other studies rely on the present topography to delineate drainage area information, required for extracting $\theta$ through Flint's law [22, 23, 30. Extracting the drainage area is challenging for Martian valley networks [22, 23, 30] due to post-emplacement basin alteration [5] (Bahia et al., 2020 (submitted)), which results in unrepresentative drainage area values. Our study relies on main stem length, which is much easier to extract than drainage area. Second, our approach is more sensitive to curvature than other techniques [21, 23, providing a better estimate of $\theta$ as well as measure of the goodness of the fit $(R M S)$ and error bounds.

We chose an $R M S=0.1$ to mark a goodness threshold, with profiles with $R M S>0.1$ discarded as too irregular to be consistent with prolonged fluvial activity. In profiles with $R M S<0.1$ we retrieve the concavity index $\theta$ (table 1 , with all our fit results presented in supplementary table 1 . Profiles that indicate fluvial landscape modification are regular $(R M S<0.1)$ and display concavity indexes $\theta>\theta_{\text {bkgrd }}$. We chose a threshold $\theta=0.45$ to identify those valley networks consistent with steady-state, provided that their concavity index was 
(1) larger than the statistical background concavity [5] and (2) different from the concavity exhibited in MOLA gridded curvature data (supplement).

The error $\delta \theta$ (supplementary table 1) includes the statistical errors of the $a_{f}$ and $b_{f}$ parameters extracted from fitting equation 13 as well as the empirical variability for Hack's exponent on Mars $\Delta h$ 23]:

$$
\delta \theta=\frac{\delta b_{f}-\Delta h \theta}{h},
$$

Similarly, the upper and lower bounds on $c$ reported are obtained using the error bounds in $\theta$ and $0.4<b<0.6$, using that:

$$
c=\frac{\theta}{(1-b)},
$$

\subsection{Supportive observational characterization of drainage-basin morphology}

Morphological analysis of valley networks, including drainage density, stream order, and valley width and length are commonly used on Mars to infer past climate and precipitation conditions $[24,25,8]$. We seek to compare inferences from valley morphometry with our concavity results, focusing our attention to three valley networks with representative profile shapes. Using image data from the High Resolution Stereo Camera (HRSC, 15 to $25 \mathrm{~m} /$ pixel) and Context Camera (CTX, $5 \mathrm{~m} /$ pixel), we compare the main valley length and width, the drainage density, and the maximum Strahler number of the valley networks considered (figure 2).

Whereas valley length is related to drainage area through Hack's law, width increases with discharge [25, 42. Mathematical considerations show that the Strahler number of a network scales like the logarithm of the number of first order tributaries [43, 42], suggesting that older networks with larger water inputs should develop higher stream orders [8] (as long as threshold stresses are 
achieved). Drainage density increases with time-integrated fluvial activity in the basin [24, 25, 8], depending on the runoff generation mechanism and the threshold for incision.

Valley length measurements are calculated from the mapped streamlines using the ArcMap 10.2.1 'Calculate Geometry' function, and we use CTX images to estimate valley width. We determine drainage density values from ArcMap 'Spatial Analyst - Line Density Tool'. Strahler numbers are obtained from Hynek et al. [8].

\section{Results and evaluation of longitudinal profiles: Modeling and ob- servation insights}

\subsection{Concavity and steady-state of valley networks}

We identify three main categories of valleys (figure 2p: (1) Those with regular profiles $R M S<0.1$ and concavity indexes larger than background $\theta>\theta_{b c k g r d}$, exemplified by Naktong Valles. These systems have concave profiles characteristic of long-term landscape modification. (2) Valley networks with regular profiles $(R M S<0.1)$ that display concavity indexes inconsistent with the long-term fluvial modification of the landscape $\left(\theta<\theta_{\text {background }}\right)$. Arda valles $(R M S<0.1, \theta=-0.3)$ is the reference example for this group. (3) Valley networks that are too irregular $(R M S>0.1)$, exemplified by Pallacopas Vallis, cannot be described successfully with models of fluvial erosion.

From the sixty-two valleys analyzed, Cusus, Himera, Al-Qahira, Evros, Naktong, and Tisia Valles have longitudinal profiles with $\theta>0.45, \theta>\theta_{\text {bkgrd }}$ (supplement, figure 4). These systems have both significantly modified their surrounding landscape and achieved profile shapes consistent with steady-state (table 1). Of the remaining valley networks analyzed, forty-seven display regular profiles $(R M S<0.1)$ with concavities not consistent with long-term fluvial ero- 

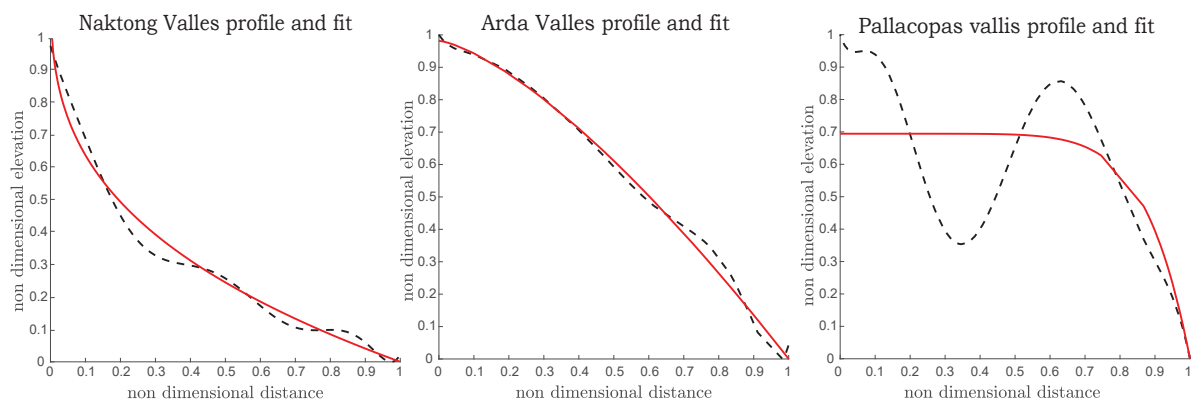

Figure 2: Valley network profiles representative of the three types: Naktong (left), Arda (middle) and Pallacopas Vallis (right). Valley network elevation profile data (dashed lines) overlapped by steady-state best fit model results (red solid line). Horizontal and vertical axes are normalized to the distance along the valley and the total topographic drop respectively.

sion 16, 19, 18. These systems are fully (i.e., Licus Valles, Arda Valles, Parana Valles), or partially convex, with presence of knickpoints (i.e., Dubis Vallis), or markedly stepped sections (e.g., Warrego Valles, Indus Valles, Auqakuh Valles). Finally, nine valley networks have irregular profiles $(R M S>0.1)$ (i.e., Pallacopas Valles). The $R M S$ and concavity index $\theta$ of the whole dataset are shown in figure 3 and in supplementary table 1 .

The statistics of our concavity indexes are broadly comparable with previous work. For example, Penido and others 23 found no consistent form for valley network profiles, ranging from concave to convex, with an average concavity index $\theta<0$. Aharonson et al. 20 found concavity indexes $\theta<0.3$, consistent with Caprarelli and Wang 22, who found $\theta<0.3$. Our work, which considers a much larger sample size, finds an average $\theta=-0.16$ with significant intervalley variability. This convex index reflects inherited topography, indicating that the duration of the fluvial activity was short compared to the landscape equilibrium timescale. This can indicate shorter episodes in a friable substrate, or much longer episodes in competent bedrock. 


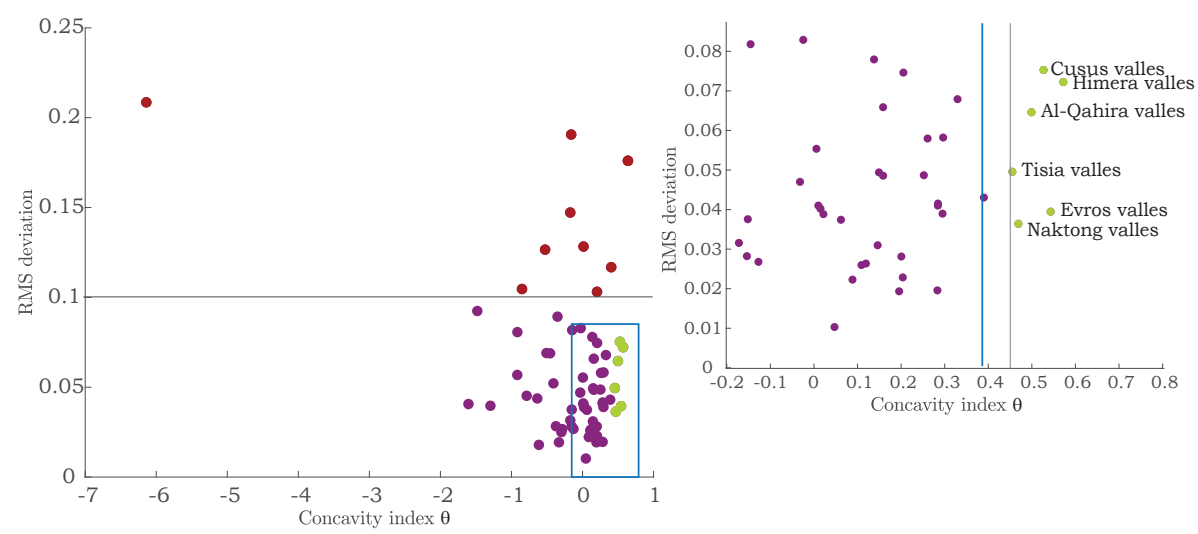

Figure 3: Concavity index $\theta$ (horizontal axis) and root mean square error between profile data and model fit $R M S$ (vertical axis) in left and right panels. Valley networks colored green are consistent with steady-state fluvial erosion (see table 1). Systems in purple are not consistent with fluvial steady-state erosion but have regular profiles $R M S<0.1$. Systems with $R M S>0.1$ are colored in red. The right shows a zoomed image of the black box, with the dashed line marking the cutoff $\theta=0.45$ set in table 1 and the blue line marking the average background concavity for Noachian terrain $\theta_{b k g r d}=0.39$.

\subsection{Water source: point source or precipitation?}

Equation 15 introduces a relationship between concavity index $\theta$ and areadischarge exponent $c$. The interpretation of $c$ is only strictly true if the valley network is consistent with steady-state, but it can be extended to systems slightly out-of-equilibrium. Table 1 compiles the subset of our data containing regular profiles $(R M S<0.1)$ and concavity above that of the background landscape, as well as those valleys consistent with steady-state $\theta>0.45$.

Valley networks consistent with steady-state concavities are also coherent with water sources and sinks distributed largely uniformly over the drainage basin $(c \approx 1)$ : this includes rain or snowfall as sources, and evaporation, sublimation, and/or uniform seepage as sinks. None of the valley networks in table 1 display point sources of water $(c \approx 0)$, implying that the runoff did not originate from springs. 
Table 1: Name, location (lat/long), fit goodness $R M S$, concavity index $\theta$, and discharge-area exponent $c$ for valley networks consistent with steady-state $(\theta>0.45)$ and some degree of landscape modification $\left(\theta>\theta_{b k g r d}\right)$. Interpretation type 1 means precipitation and losses were uniformly distributed around the basin area $c \approx 1$ ). Type 2 is mostly uniform precipitation and losses $(c<0.95)$, and type 3 is non-uniform precipitation or losses $(c<0.9)$.

\begin{tabular}{llllllll}
\hline Name & lat & long & $R M S$ & $\theta$ & $\theta_{\text {bkgrd }}$ & $c$ & interpretation \\
\hline$\theta \approx 0.5$ & & & & & & & \\
Cusus Valles & 14.30 & 50.50 & 0.08 & 0.53 & 0.38 & 1 & Type 1 \\
Himera Valles & -21.40 & -22.80 & 0.07 & 0.57 & 0.36 & 1.1 & Type 1 \\
Al-Qahira Valles & -18.20 & 162.50 & 0.06 & 0.5 & 0.38 & 1 & Type 1 \\
Evros Valles & -12.60 & 13.90 & 0.04 & 0.54 & 0.38 & 1.1 & Type 1 \\
Naktong Valles & 5.20 & 32.90 & 0.04 & 0.47 & 0.38 & 0.94 & Type 2 \\
Tisia Valles & -4.96 & 44.30 & 0.05 & 0.46 & 0.38 & 0.91 & Type 2 \\
\hline 0.45 $>\theta \geq \theta_{b k g r d}$ & & & & & & & \\
Protva Valles & -29.00 & -60.60 & 0.04 & 0.39 & 0.39 & 0.78 & Type 3 \\
\hline
\end{tabular}

\subsection{Geomorphological Analysis of Naktong Valles, Arda Valles and Pallacopas} Vallis

We contrast the morphological analysis results for the three profile endmembers (section 4.1) with our concavity findings. Figure 4 shows the drainage density, main valley length, and Strahler number of Naktong, Arda, and Pallacopas Valles.

Naktong Valles (figure 4 a) originates south of Janssen crater at an altitude of $1813 \mathrm{~m}$ and width of $\approx 2090 \mathrm{~m}$, and terminates at an altitude of $-297 \mathrm{~m}$ with a width of $\approx 5000 \mathrm{~m}$ south of Argo crater. Naktong valles' longitudinal profile is smooth $(R M S<0.1)$ and concave, consistent with fluvial steadystate $(\theta=0.47 \pm 0.03)$. This valley network has the largest main stem length $(1170.8 \mathrm{~km})$, drainage area $\left(0.046 \mathrm{~km}^{-1}\right)$ and Strahler number $(6)$ of the three valleys described here. All these values are considerably larger than average for the Martian valley networks [8]. Figure 44 s shows the dendritic planform of Naktong Valles, with river terraces identified in the downstream reaches of the system (see e.g., figure $4 \mathrm{~A}$ ).

Arda Valles $(4 \mathrm{~B})$, displays a regular profile $(R M S<0.1)$, but concavity index $(\theta=-0.3 \pm 0.08)$ inconsistent with steady-state. It is the shortest main 


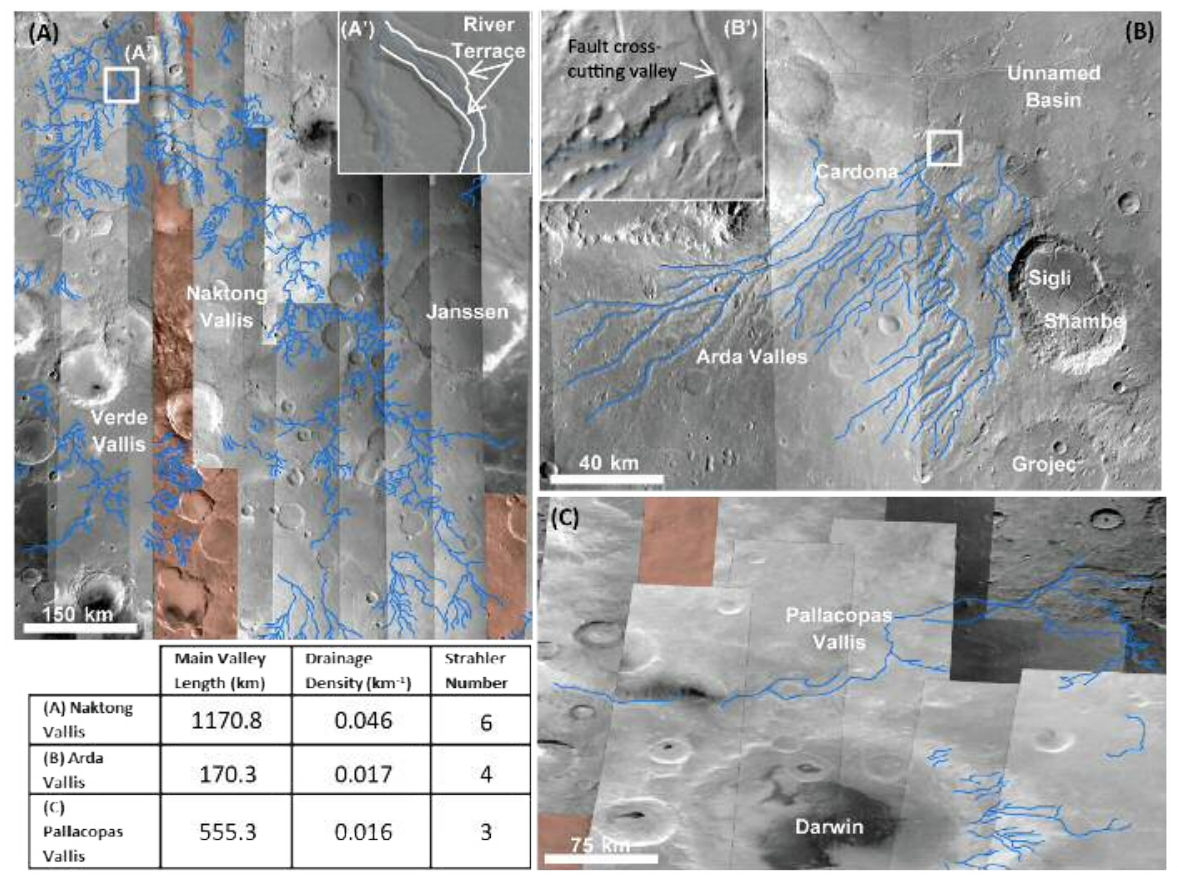

Figure 4: CTX imagery overlapped with valley networks streamlines showing main stem length, drainage density, and Strahler number for (A) Naktong Vallis with potential river terraces (A), (B) Arda Valles, and (C) Pallacopas Vallis.

stem of the three systems investigated $(170.3 \mathrm{~km})$. Compared to Naktong, Arda Valles has a lower drainage density $\left(0.017 \mathrm{~km}^{-1}\right)$, Strahler number (4) and lacks observable river terraces. The drainage density of Arda Valles is comparable to the average value for valley networks incising Noachian terrains $\left(0.0115 \mathrm{~km}^{-1}\right.$ $[8])$. The Strahler number reported is higher than average $[8](\approx 1.5)$, an so is the length of the main stem (average $13.1 \mathrm{~km}$ ). Arda Valles' source is located at an elevation of $59 \mathrm{~m}$, and it terminates in an unnamed basin (altitude of -1861 $\mathrm{m})$, flowing from SW to NE. There is little difference between source width $(\approx$ $1900 \mathrm{~m})$ and termination width $(\approx 1990 \mathrm{~m})$. Similar to Naktong, Arda Valles displays a well-preserved dendritic valley planform.

Figure $4 \mathrm{C}$ shows Pallacopas Vallis' distinctive trellis planform, heavily de- 
graded and disjointed in areas. Although Pallacopas has a much longer main stem $(555.3 \mathrm{~km})$ than Arda Valles, its drainage density $\left(0.016 \mathrm{~km}^{-1}\right)$ and Strahler number (3) are lower. The main stem of Pallacopas Vallis (figure $4 \mathrm{C}$ ) has a source altitude of $619 \mathrm{~m}$ and width of $\approx 6200 \mathrm{~m}$, termination altitude of $197 \mathrm{~m}$ and terminal width of $\approx 6940 \mathrm{~m}$. Our results yield $\theta=-6 \pm 3$ with an $R M S=0.21$. These observations are coherent with the concavity results.

\section{Mature valley networks and water sources: discussion and impli- cations}

\subsection{Steady-state valley network distribution}

Figure 5 displays our results on a global map of Mars. Valley networks with $\theta \approx 0.5$ lie mostly along the narrow topographic belt linking the Noachian Highlands with Arabia Terra, as well as Aeolis outside of this corridor (supplement). These systems are consistent with uniform precipitation (snow or rain) and uniform water losses (table $1, c \approx 1)$. Protva valles $(\theta=0.39)$ also produced landscape modification. We find a discharge-area exponent $c=0.78$ for Protva, possibly indicating non-uniform precipitation such as contributions from localized storms and springs, and/or with localized losses in the network.

Valley networks with $R M S<0.1$ and $\theta<\theta_{b k g r d}$ failed to create an erosional drainage basin. These examples comprise 47 of 62 valleys, indicating that the majority of valley networks only produced minimal landscape modification. Thus, the duration of fluvial erosion was much shorter than the landscape equilibrium timescale. These characteristics represent an important distinction with terrestrial river valleys.

Finally, valley networks with irregular profiles $(R M S>0.1)$ comprise 9 out of 62 valleys analyzed. They either have been substantially modified by tectonic processes without visible surface expression, or were not carved by 


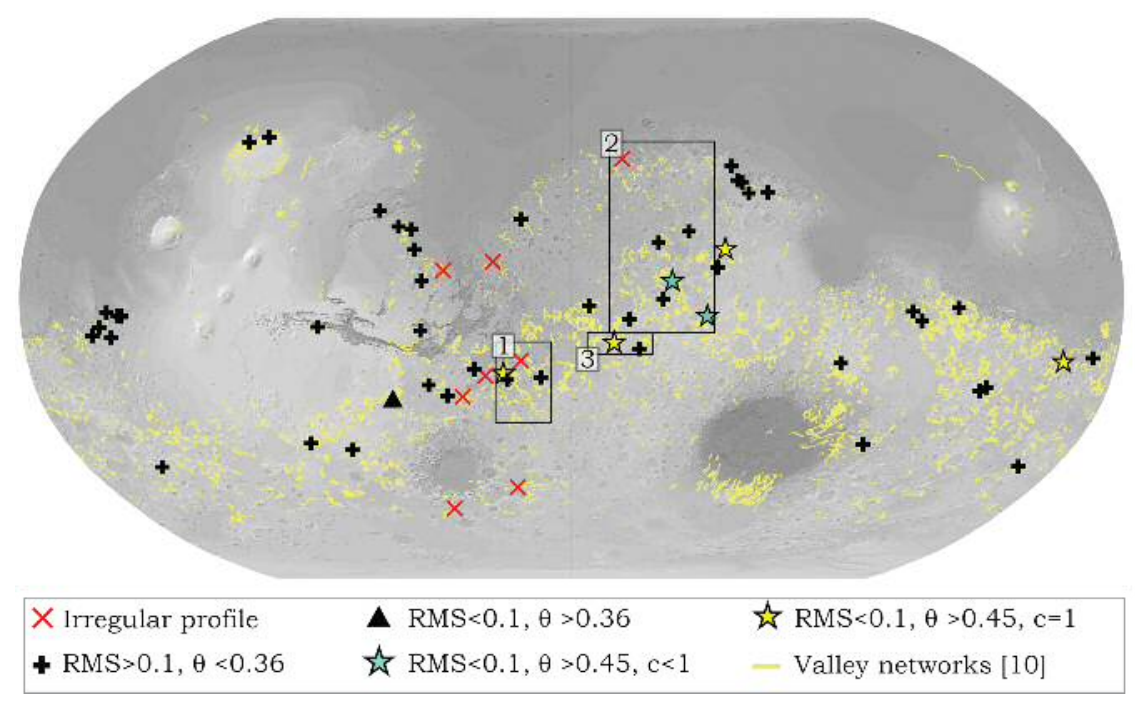

Figure 5: Global map of Mars (MOLA) and valley networks streamlines [8]. Red crosses show valleys with irregular profiles $(R M S>0.1)$. Black crosses show valleys with little fluvial modification ( $\left.R M S<0.1, \theta<\theta_{b k g r d}\right)$ and concavity comparable to initial conditions. Triangles show valleys with regular profiles, concavity differing from background suggesting landscape modification but not steady-state $\left(R M S<0.1,0.45>\theta>\theta_{b k g r d}\right)$. Stars show valleys with regular profiles consistent with steady-state concavities $R M S<0.1, \theta>0.45$, and yellow and green stars indicate discharge-area exponents $c \approx 1$ and $c<1$ ). Areas numbered 1 to 3 are described in section 5.1.1.

fluvial processes (Grau Galofre et al., submitted). The majority of irregular valleys are located following the Argyre-Margaritifer-Oxia Palus belt, draining into the Uzboi-Ladon-Morava outflow system, and in Ismenus Lacus.

\subsubsection{Results by drainage basin}

The proximity between "developed" (stars, figure 5) and "underdeveloped" (triangles and black crosses) valley networks indicates that proximal valleys can be in different stages of landscape evolution. Here we discuss three examples (figure 5, areas 1-3), of which two are shown in figure 6 (context for all valley networks is in supplementary table 2). The first case (1) is the Loire-SamaraParana system, of which only one tributary (Himera valles, $\theta=0.57 \pm 0.02$ ) is consistent with fluvial steady-state. The three main stems in the basin display 
concavity indexes far from steady. Parana valles' profile is smooth but convex $(\theta=-0.37 \pm 0.06)$, Loire valles' profile is convex and highly irregular $(\theta=$ $-0.5 \pm 0.1, R M S=0.13)$, and Samara valles' is smooth and slightly concave $(\theta=0.2 \pm 0.01)$.

Parana valles drains into Parana basin, a chaotic basin assumed to be a relict paleolake, from which the main stem of Loire valles emerges [44]. Just before its outlet, Loire valles merges with the main stem of Samara valles to drain into Morava valles, part of the Uzboi-Ladon-Morava outflow channel system 45. When interrogating the longitudinal profile of a combined Parana-Loire main stem, we find an overall irregular $(R M S>0.1)$ and concave profile $(\theta=$ $0.3 \pm 0.1)$, suggesting that the combined system responded to a single base-level elevation set by Morava valles. This combined profile shows a sharp change in curvature at Parana basin, indicating that this system was not well integrated and it did not evolve synchronously to steady-state. The change of curvature located in Parana basin and the volume of alluvium accumulated 45, moreover, could indicate the presence of a dam.

Another case of interest is the Naktong-Scamander-Mamers system (NSM 52 ) shown in figure 6 ( $\mathrm{a}$ and b), one of the largest drainages on Mars [46]. Including Tisia valles, the basin elevation drops from $2,500 \mathrm{~m}$ at the headwaters of Tisia to $-3,500 \mathrm{~m}$ at the lowest point of Mamers. Activity in Naktong, Scamander, and Mamers vallis is dated from the early Hesperian period [47, 46], whereas activity in Tisia valles has not been dated. The four valley networks drain in the same overall direction (SE-NW) and are situated in close spatial proximity, but display distinct planforms and profiles. Mamers and Scamander valles have concavity values of $\theta=0.20 \pm 0.04$, and $\theta=-0.79 \pm 0.1$ respectively, far from those reported for Naktong $(\theta=0.47 \pm 0.03)$ and Tisia $(\theta=0.46 \pm 0.02)$, which are both consistent with steady-state. Mamers profile shows multiple 

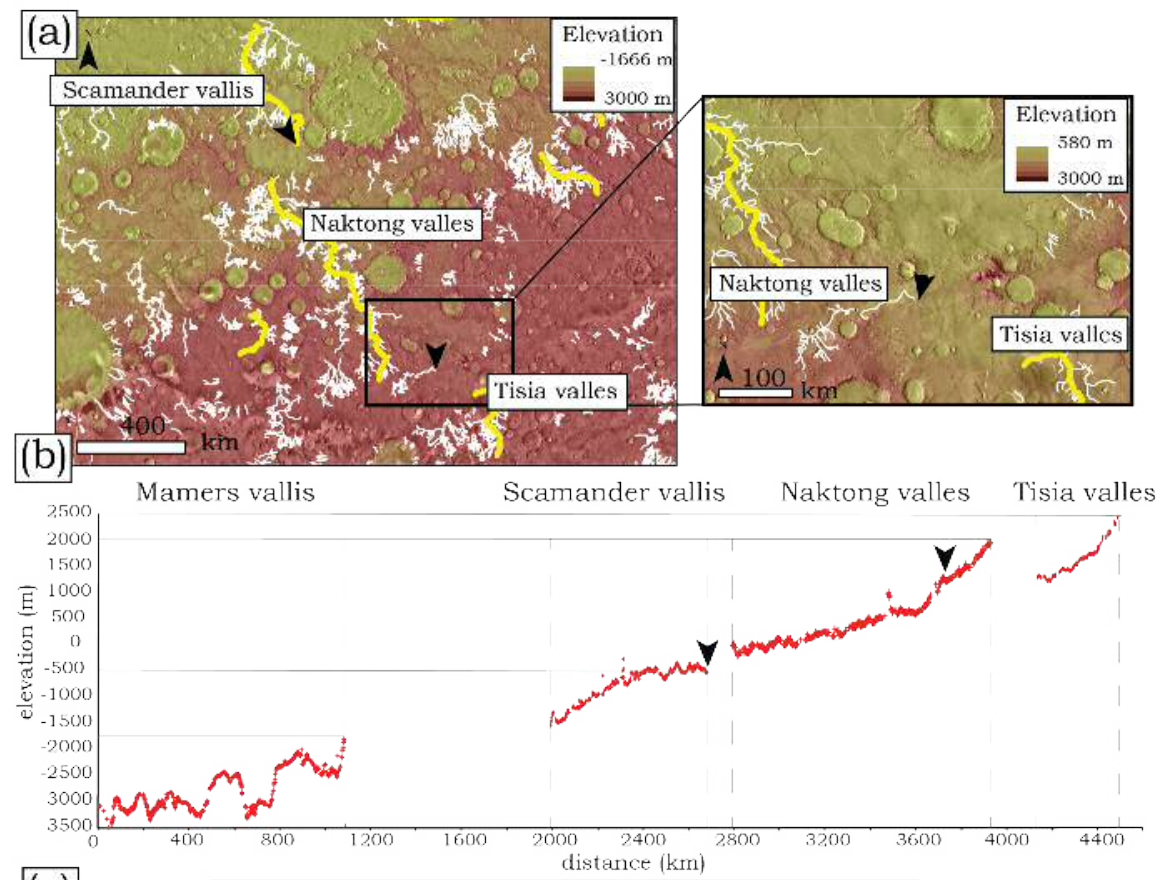

(c)
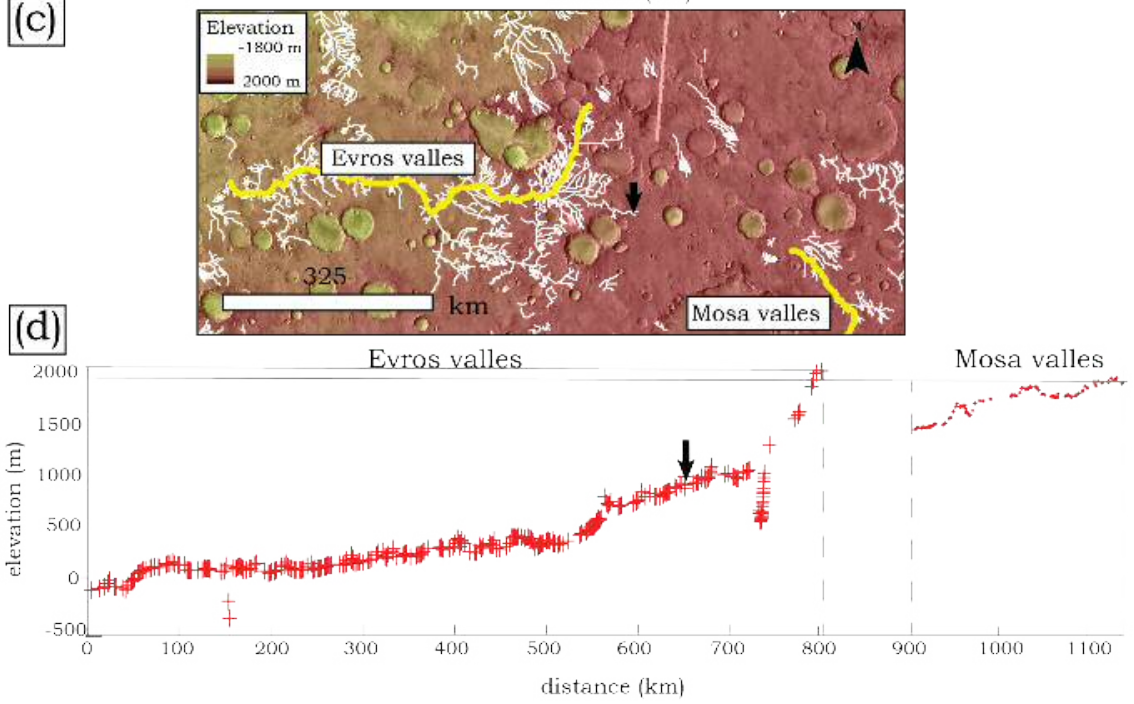

Figure 6: Integrated basin analysis for the Tisia-Naktong-Scamander (TNS) and the EvrosMosa (EM) systems. (a) shows the planform (THEMIS + MOLA), network streamlines [8] and our own streamline (yellow) for TNS, with closeup (right) showing the Tisia-Naktong proposed junction. Junctions are marked using black arrows. (b) TNS Longitudinal profiles (including Mamers), $\mathrm{x}$ axis is distance $(\mathrm{km})$, y axis is elevation $(\mathrm{m})$. (c) planform morphology (THEMIS + MOLA) of the EM system, showing the proposed junction point with an arrow. (d) longitudinal profile of Mosa and Evros valles. 
slope reversals that are hardly consistent with fluvial erosion (figure 6b), suggesting instead erosion or reworking by glacial processes and mass wasting [48]. Comparing Mamers and Naktong valles profiles and morphology, we find the evidence lacking to make a case for their belonging in the same fluvial drainage basin.

In contrast, Scamander valles is connected with Naktong valles' outlet through a sedimentary basin (figure 6). In spite of the spatial proximity, the differences between Naktongs and Scamanders concavity index suggest that the total time of activity was much longer for Naktong than Scamander. This result is supported by Scamander's sparse network with small stream orders and a large main stem. The combined observations support the formation hypothesis involving flooding or basin overflow [4], resulting in short-lived fluvial activity in Scamander.

Tisia valles has a smooth concave profile consistent with steady-state $(\theta=$ $0.46 \pm 0.02)$ and discharge-area exponent indicating steady, uniform precipitation $0.76 \leq c_{\text {Tisia }} \leq 1.14$ similar to that of Naktong $0.78 \leq c_{\text {Naktong }} \leq 1.17$ Although Tisia is much shorter, the comparable morphology between Tisia and Naktong (similarly sized tributaries and large network stream orders) suggest that the two valleys responded to analogous environmental conditions of uniform precipitation. Moreover, topographic data shows a possible connection between Tisia valles and a Naktong tributary (figure 6), suggesting that Tisia and Naktong may have been one integrated drainage system.

The last basin we consider is the Evros-Mosa system (figures 53,6 c and d). This is an extensive $\left(56,000 \mathrm{~km}^{2}\right.$ [5]) drainage system located in western Terra Sabaea [49, 22, with a total elevation drop from $\approx 2,000 \mathrm{~m}$ down to $\approx-100$ m. Activity in the valleys is dated Late Noachian to Early Hesperian [47, 46]. Although the proximity between Mosa's outlet and an Evros' tributary headwa- 
ters suggests a connection existed [9], their profiles are very disparate (figure 6). Evros valles' profile is smooth and concave $(\theta=0.54 \pm 0.03, R M S=0.04)$, whereas Mosa valles' profile is convex $\theta=-0.9 \pm 0.3$ and more irregular $(R M S=0.08)$. The differences in profile between Mosa and Evros are also reflected in their morphology: Mosa shows smaller tributary densities and stream order than Evros [8], as well as discrepancies in main stem depth and width between Mosa's outlet and the point of junction with Evros (black arrow). Given the lower concavity and tributary density, we infer that Mosa valles was active for a much shorter period than Evros valles, either incising only during a reactivation of the Evros system or lacking a later period of activity.

Our estimation of the area-discharge exponent $1.36 \leq c \leq 0.91$ suggests uniform precipitation over the Evros basin, in agreement with a terminal episode of intense fluvial activity [9]. The climate transition suggested by Howard et al., 2005 9, however, cannot be validated from the shape of Evros valles. Profile knickpoints, which should appear in response to a climate transition [16, 50] from an arid climate (lower concavity) to a wetter climate (higher concavity) [50], are absent from the profile. Evros therefore was active for long enough under the new climate conditions to achieve steady state, or was not affected by a climatic change.

It is important to note that previous studies report different concavity exponents for Evros valles, both among them and compared with ours: $\theta=-0.61$ [21] and $\theta=0.23[22$. These discrepancies can be attributed to differing choices of main stems [21] and different interpretations of drainage area boundaries, which the same authors recognize to be problematic [22], as well as the sensitive dependence of their methodology on derivatives of the MOLA gridded DEM [22]. Due to the sensitivity of Flint's law to drainage area, large uncertainties in the later can yield vastly different and possibly unreliable results. 


\subsection{Distribution with respect to surface tectonics}

All valley networks with profiles consistent with fluvial steady-state (figure 7. black stars) are in areas with sparce surface structures [51. Valley networks in regions with high density of reported superficial faults [51, such as Warrego Valles, are often not in steady-state and display abrupt changes in profile slope, stepped sections, and knickpoints. Although this is consistent with observations of terrestrial river valleys in regions of rapid uplift or sudden base level fall [16], more work is necessary to establish a causal relationship.

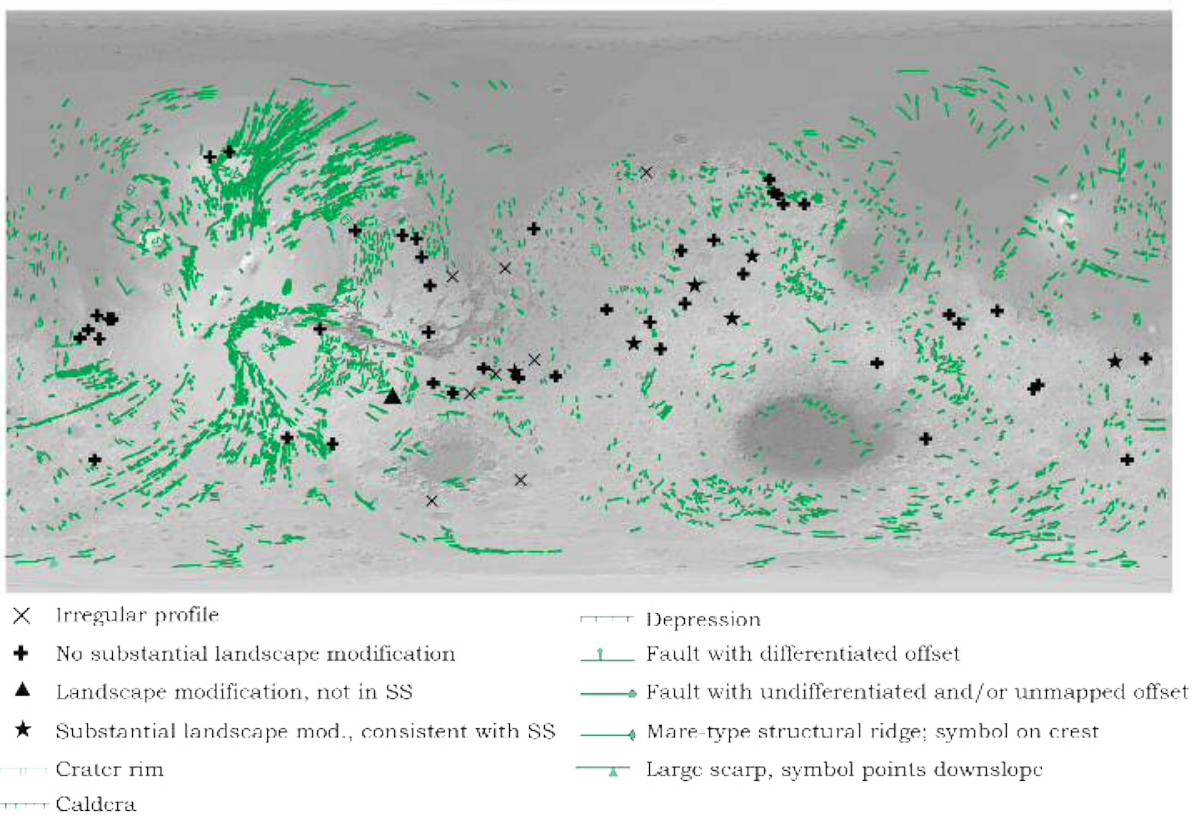

Figure 7: Global map of Mars (MOLA) overlapped by the surface tectonic structures as mapped by [51], showing the location of the valley networks in our study, their classification as described in the text and the caption. Note the lack of regular valley networks close to significant surface tectonic expressions. 


\subsection{Comparison of theoretical and observational insights on valley network} morphologies.

Here we discuss network maturity for the three end-member valleys discussed in section 5.1 (Naktong, Arda, and Pallacopas) comparatively using drainage density, Strahler order, and profile concavity results. The drainage density of Naktong Valles is the highest among the three systems analyzed, consistently with it having $\theta \approx 0.5$. However, Naktong's drainage density is an order of magnitude below the highest density values reported, e.g., for Ravius Valles. Ravius Valles' concavity is, however, far from steady-state values $\theta \approx 0.09 \pm$ $0.02, R M S=0.02$, suggesting that care should be taken when making a case for valley maturity solely on the basis of drainage density. Additionally, whereas valley networks consistent with steady-state concavities have Strahler orders much larger than average (above 4 in all cases), the reciprocal is not true: Some of the highest Strahler order systems $(>5)$, such as Loire or Parana Valles, have convex or irregular profiles that are inconsistent with fluvial steady-state (supplement).

Naktong displays an increase in width from source to termination (section 4.3) typical of a fluvial system formed via surface runoff and indicative of an increase in discharge down-slope. Naktong's higher-than-average drainage density and Strahler number [8] are consistent with greater water fluxes and/or a longer activity span. Additional evidence of sustained fluvial activity within Naktong Valles is the presence of possible river terraces (figure $4 \mathrm{~A}$ and $\mathrm{A}^{\prime}$ ), potentially indicative of periodic flooding and incision.

Arda Valles has a convex profile inconsistent with fluvial steady-state $(\theta=$ $-0.3 \pm 0.08)$. Arda enters an unnamed basin part of the Uzboi-Ladon-Morava system, with no visible alteration of the initial basin rim topography (figure 4 B), supporting our results. The low drainage density and Strahler number of 
this valley network also agree with a lack of sustained fluvial activity. Additionally, Arda Valles shows a negligible increase in width from source to termination, indicating it experienced a remarkably small downstream discharge growth despite having a Strahler number equal to 4 . This apparent lack of downstream cumulative discharge may be a consequence of substantial evaporation, water seepage, or different timing of tributary activity. Finally, the presence of a fault cross-cutting the termination of Arda Valles indicates that this area was locally tectonically active post-emplacement of the valley network (Late Noachian-Early Hesperian [47]). However, this activity appears to have caused insignificant alterations to the basin-scale valley profile, given the otherwise remarkably smooth profile (figure 4).

The longitudinal profile of Pallacopas Vallis is irregular $(R M S<0.1)$ with large undulations (figure 2). Whereas degradation may explain to some extend why Pallacopas Vallis does not display a regular profile, its disconnected stem far, from surface tectonics (figure 7), is also hardly consistent with formation via surface runoff. Pallacopas Vallis displays a low drainage density and Strahler number (figure 4). Combining these factors with its high southern latitude and the presence of profile reversals, the formation of Pallacopas Vallis is more consistent with a subglacial origin (Grau Galofre et al., submitted).

\section{Conclusions}

In this study we use an observational and modeling approach to address two questions: Were valley networks active for long enough to significantly alter the landscape and achieve steady-state? What water sources are most consistent with morphology and profile shape? To proceed, we use a generalized solution describing steady-state river profiles to make predictions for the form of valley networks in equilibrium [17. We then build the physical intuition necessary to 
interpret concavity and the origin and water source to the basin.

We use MOLA laser altimeter point PEDR data and high resolution valley network streamlines to derive valley longitudinal profiles. To interrogate each individual profile, we perform a non-linear fit directly between profile and steady-state solution. This novel technique enables the extraction of the concavity index without measuring the drainage area, which is problematic to estimate for the valley networks. Our results reveal that six valley networks out of 62 analyzed are consistent with fluvial steady-state: Naktong, Evros, Tisia, Al-Qahira, Cusus, and Himera valles. Four of these valleys are clustered in the corners of Syrtis Major-Arabia-Sinus Sabaeus regions. Another 9 valley networks show irregular profiles with undulating or disrupted sections, located mostly following the Uzboi-Ladon-Morava megasystem from the south of Argyre into the lowlands. The vast majority of the valleys analyzed (47 out of 62) did not achieve any substantial basin development, indicating the lack of protracted fluvial activity at a global scale.

Our findings yield disparity in concavity indexes of valley networks belonging in the same integrated basins, indicating different stages of landscape evolution and lack of synchronous valley development. Our results highlight the global lack of protracted fluvial activity on Mars, but identify for the first time the presence of valley networks consistent with steady-state. The Naktong and Evros basins, in particular, should be considered as systems with long-term fluvial activity.

Supplementary Information This manuscript contains supplementary information consisting on supplementary methods, supplementary table 1, and supplementary table 2 .

Acknowledgments A. Grau Galofre and A. M. Jellinek were supported through the NSERC Discovery grant program. A. Grau Galofre received sup- 
port also through the Exploration Fellowship program of the School of Earth and Space Exploration (Arizona State University). Our appreciation goes to professor Robert Craddock for helpful reviews, and to the MJ-CJ research group for constant support.

Competing Interests The authors declare that they have no competing interests.

Correspondence Correspondence and requests for materials should be addressed to Anna Grau Galofre (email: agraugal@asu.edu).

\section{References}

[1] R. A. Craddock, A. D. Howard, The case for rainfall on a warm, wet early Mars, Journal of Geophysical Research: Planets 107 (E11) (2002).

[2] R. D. Wordsworth, L. Kerber, R. T. Pierrehumbert, F. Forget, J. W. Head, Comparison of warm and wet and cold and icy scenarios for early Mars in a 3-D climate model, Journal of Geophysical Research: Planets 120 (6) (2015) 1201-1219.

[3] M. H. Carr, The Martian drainage system and the origin of valley networks and fretted channels, Journal of Geophysical Research: Planets 100 (E4) (1995) 7479-7507.

[4] V. C. Gulick, Origin of the valley networks on Mars: A hydrological perspective, Geomorphology 37 (3-4) (2001) 241-268.

[5] T. Stepinski, M. Collier, P. McGovern, S. Clifford, Martian geomorphology from fractal analysis of drainage networks, Journal of Geophysical Research: Planets 109 (E2) (2004).

[6] R. P. Irwin, A. D. Howard, R. A. Craddock, J. M. Moore, An intense terminal epoch of widespread fluvial activity on early Mars: 2. Increased 
runoff and paleolake development, Journal of Geophysical Research: Planets 110 (E12) (2005).

[7] A. D. Howard, Simulating the development of Martian highland landscapes through the interaction of impact cratering, fluvial erosion, and variable hydrologic forcing, Geomorphology 91 (3-4) (2007) 332-363.

[8] B. M. Hynek, M. Beach, M. R. Hoke, Updated global map of Martian valley networks and implications for climate and hydrologic processes, Journal of Geophysical Research: Planets 115 (E9) (2010).

[9] A. D. Howard, J. M. Moore, R. P. Irwin, An intense terminal epoch of widespread fluvial activity on early Mars: 1. Valley network incision and associated deposits, Journal of Geophysical Research: Planets 110 (E12) (2005).

[10] M. H. Carr, J. W. Head, Basal melting of snow on early Mars: A possible origin of some valley networks, Geophysical Research Letters 30 (24) (2003).

[11] J. E. Laity, M. C. Malin, Sapping processes and the development of theaterheaded valley networks on the Colorado Plateau, Geological Society of America Bulletin 96 (2) (1985) 203-217.

[12] M. C. Malin, M. H. Carr, Groundwater formation of Martian valleys, Nature 397 (6720) (1999) 589.

[13] M. P. Lamb, A. D. Howard, J. Johnson, K. X. Whipple, W. E. Dietrich, J. T. Perron, Can springs cut canyons into rock?, Journal of Geophysical Research: Planets 111 (E7) (2006).

[14] A. D. Howard, A detachment-limited model of drainage basin evolution, Water resources research 30 (7) (1994) 2261-2285. 
[15] L. Sklar, W. E. Dietrich, River longitudinal profiles and bedrock incision models: Stream power and the influence of sediment supply, Wiley Online Library, 1998.

[16] K. X. Whipple, G. E. Tucker, Dynamics of the stream-power river incision model: Implications for height limits of mountain ranges, landscape response timescales, and research needs, Journal of Geophysical Research: Solid Earth 104 (B8) (1999) 17661-17674.

[17] K. X. Whipple, G. E. Tucker, Implications of sediment-flux-dependent river incision models for landscape evolution, Journal of Geophysical Research: Solid Earth 107 (B2) (2002) ETG-3.

[18] A. D. Wickert, T. F. Schildgen, Long-profile evolution of transport-limited gravel-bed rivers (2019).

[19] K. X. Whipple, Bedrock rivers and the geomorphology of active orogens, Annu. Rev. Earth Planet. Sci. 32 (2004) 151-185.

[20] O. Aharonson, M. T. Zuber, D. H. Rothman, N. Schorghofer, K. X. Whipple, Drainage basins and channel incision on Mars, Proceedings of the National Academy of Sciences 99 (4) (2002) 1780-1783.

[21] S. M. Som, D. R. Montgomery, H. M. Greenberg, Scaling relations for large Martian valleys, Journal of Geophysical Research: Planets 114 (E2) (2009).

[22] G. Caprarelli, B. Wang, Wet Mars implications of revised scaling calculations for Evros Vallis, Australian Journal of Earth Sciences 59 (2) (2012) 263-276.

[23] J. C. Penido, C. I. Fassett, S. M. Som, Scaling relationships and concavity of small valley networks on Mars, Planetary and Space Science 75 (2013) $105-116$. 
[24] M. H. Carr, F. C. Chuang, Martian drainage densities, Journal of Geophysical Research: Planets 102 (E4) (1997) 9145-9152.

[25] B. M. Hynek, R. J. Phillips, New data reveal mature, integrated drainage systems on Mars indicative of past precipitation, Geology 31 (9) (2003) $757-760$.

[26] R. C. Kochel, J. F. Piper, Morphology of large valleys on Hawaii: Evidence for groundwater sapping and comparisons with Martian valleys, Journal of Geophysical Research: Solid Earth 91 (B13) (1986).

[27] A. D. Howard, Groundwater sapping experiments and modeling, Sapping Features of the Colorado Plateau: A Comparative Planetary Geology Field Guide 491 (1988) 71-83.

[28] O. Devauchelle, A. Petroff, A. Lobkovsky, D. H. Rothman, Longitudinal profile of channels cut by springs, Journal of Fluid Mechanics 667 (2011) $38-47$.

[29] J. T. Hack, Studies of longitudinal stream profiles in Virginia and Maryland, Vol. 294, US Government Printing Office, 1957.

[30] R. Bahia, M. Jones, S. Covey-Crump, N. Mitchell, The Application of Hack's Law and Flint's Law to Martian Valley Networks and Its Implications for the Noachian Climate, in: Lunar and Planetary Science Conference, Vol. 50, 2019.

[31] H. H. Savenije, The width of a bankfull channel; Lacey's formula explained, Journal of Hydrology 276 (1) (2003) 176-183.

[32] G. Parker, P. R. Wilcock, C. Paola, W. E. Dietrich, J. Pitlick, Physical basis for quasi-universal relations describing bankfull hydraulic geometry 
of single-thread gravel bed rivers, Journal of Geophysical Research: Earth Surface 112 (F4) (2007).

[33] J. M. Turowski, N. Hovius, A. Wilson, M.-J. Horng, Hydraulic geometry, river sediment and the definition of bedrock channels, Geomorphology 99 (1-4) (2008) 26-38.

[34] V. K. Gupta, D. R. Dawdy, Physical interpretations of regional variations in the scaling exponents of flood quantiles, Hydrological Processes 9 (3-4) (1995) 347-361.

[35] K. T. Lee, N.-C. Chen, B. I. Gartsman, Impact of stream network structure on the transition break of peak flows, Journal of hydrology 367 (3-4) (2009) $283-292$.

[36] P. B. Sólyom, G. E. Tucker, Effect of limited storm duration on landscape evolution, drainage basin geometry, and hydrograph shapes, Journal of Geophysical Research: Earth Surface 109 (F3) (2004).

[37] M.-k. Woo, Hydrology of a drainage basin in the Canadian High Arctic, Annals of the Association of American Geographers 73 (4) (1983) 577-596.

[38] X. Huang, J. D. Niemann, Modelling the potential impacts of groundwater hydrology on long-term drainage basin evolution, Earth Surface Processes and Landforms: The Journal of the British Geomorphological Research Group 31 (14) (2006) 1802-1823.

[39] T. Richards, Physics and chemistry of snowfall and snow distribution, in: The role of snow and ice in hydrology. Proceedings of the Banff symposia, 1972, Vol. 1, 1972, pp. 1-13.

[40] V. Ansan, N. Mangold, P. Masson, E. Gailhardis, G. Neukum, Topography of valley networks on Mars from Mars Express High Resolution Stereo 
Camera digital elevation models, Journal of Geophysical Research: Planets 113 (E07006) (2008).

[41] G. A. Neumann, J. B. Abshire, O. Aharonson, J. B. Garvin, X. Sun, M. T. Zuber, Mars Orbiter Laser Altimeter pulse width measurements and footprint-scale roughness, Geophysical research letters 30 (11) (2003).

[42] A. Grau Galofre, M. A. Jellinek, The geometry and complexity of spatial patterns of terrestrial channel networks: Distinctive fingerprints of erosional regimes., Journal of Geophysical Research: Earth Surface 122 (4) (2017) 1037-1059.

[43] A. Meir, J. Moon, J. Pounder, On the order of random channel networks, SIAM Journal on Algebraic Discrete Methods 1 (1) (1980) 25-33.

[44] C. J. Barnhart, A. D. Howard, J. M. Moore, Long-term precipitation and late-stage valley network formation: Landform simulations of Parana Basin, Mars, Journal of Geophysical Research: Planets 114 (E1) (2009).

[45] J. A. Grant, T. J. Parker, Drainage evolution in the Margaritifer Sinus region, Mars, Journal of Geophysical Research: Planets 107 (E9) (2002) $4-1$.

[46] S. Bouley, V. Ansan, N. Mangold, P. Masson, G. Neukum, Fluvial morphology of Naktong Vallis, Mars: A late activity with multiple processes, Planetary and Space Science 57 (8-9) (2009) 982-999.

[47] C. I. Fassett, J. W. Head, Valley network-fed, open-basin lakes on Mars: Distribution and implications for Noachian surface and subsurface hydrology, Icarus 198 (1) (2008) 37-56.

[48] A. Kress, J. W. Head, D. Marchant, The nature of the transition from lobate debris aprons to lineated valley fill: Mamers Valles, Northern Arabia 
${ }_{737}$ TerraDeuteronilus Mensae region on Mars., in: Lunar Planet. Sci. 37., no.

$738 \quad$ Abstract 1323, 2006.

[49] R. P. Irwin III, R. A. Craddock, A. D. Howard, H. L. Flemming, Topographic influences on development of Martian valley networks, Journal of Geophysical Research: Planets 116 (E2) (2011).

[50] B. J. Zaprowski, F. J. Pazzaglia, E. B. Evenson, Climatic influences on profile concavity and river incision, Journal of Geophysical Research: Earth Surface 110 (F3) (2005).

[51] K. L. Tanaka, J. A. Skinner, J. M. Dohm, R. P. Irwin III, E. J. Kolb, C. M. Fortezzo, T. Platz, G. G. Michael, T. Hare, Geologic map of Mars, US Department of the Interior, US Geological Survey, 2014. 